\title{
Analysis of the Treatment of Acute Myocardial Infarction Using Ambulance Records in Japanese Cities
}

\author{
Nobusada Funabashi, MD; Masayuki Shima, MD*; \\ Motoaki Adachi, MD*; Shigeru Watanabe, MD; Yoshiaki Masuda, MD
}

\begin{abstract}
By means of ambulance records, the current state of medical services for the treatment of acute myocardial infarction (AMI) was investigated in Chiba City and Ichihara City, Japan. From all patients transported by ambulance personnel in $1992(\mathrm{n}=31,191), 388$ patients who were admitted within 2 weeks after the onset were studied. Types of admitting institution, diagnoses, medical treatments and prognoses were investigated. According to medical records, 168 patients fulfilled the criteria of definite AMI and were admitted alive. Percutaneous transluminal coronary angioplasty (PTCA) and recanalization (PTCR) were performed on 54 and 6 patients, respectively. The hospital case-fatality rates were lower in the patients who underwent emergency PTCA or PTCR than in the others. Emergency PTCA or PTCR, and admission to coronary care units (CCU) or institutions equipped with coronary angiography, decreased the fatality risk, even after considering age, sex, and disease severity. These results show the importance of the selection of institutions for AMI patients. Because $40 \%$ of definite AMI patients were sent to institutions without $\mathrm{CCU}$, it is essential that enough CCU are available through an improvement in cooperation between the various types of institutions, and in the proper transfer of AMI patients to CCU (Jpn Circ J 1999; 63: 170-176)
\end{abstract}

Key Words: Acute myocardial infarction; Ambulance records; Case-fatality rates; MONICA criteria; Recanalization therapy

$\mathbf{T}$ he usefulness of recanalization therapy that includes thrombolytic therapy and emergency percutaneous transluminal coronary angioplasty (PTCA) for acute myocardial infarction (AMI) is recognized, and this procedure is widely performed as a primary treatment. Decreases in the case-fatality rates from AMI from approximately $30 \%$ to $10 \%$ have been reported with this therapy. However, many more institutions that specialize in cardiology and offer these procedures are needed. Average rates of fatality within 28 days after AMI were $48 \%$ for males and $54 \%$ for females according to the multinational monitoring of trends and determinants in cardiovascular disease (MONICA) project (21 countries; age 35-64 years)? In spite of the usefulness of recanalization therapy, it has not been available for all eligible AMI patients worldwide. In the US, thrombolysis is considered the first line of therapy for AMI in suitable patients, but in a recent report it was used in only $70 \%$ of ideal candidates? In Japan, the mortality rate for AMI is low compared with that in the US or European countries, and there is a concentration of specialty institutions in urban districts at which patients can conveniently receive emergency PTCA or percutaneous transluminal coronary recanalization (PTCR) treatment.

Although many reports describe results of medical treatment at specific institutions, there have been few investigations to determine the actual treatment situation for patients in an entire area. In order to determine treatment strategies

(Received April 30, 1998; revised manuscript received November 6, 1998; accepted November 26, 1998)

Third Department of Internal Medicine and *Department of Public Health, Chiba University School of Medicine, Chiba, Japan

Mailing address: Masayuki Shima, MD, Department of Public Health, Chiba University School of Medicine, 1-8-1 Inohana, Chuoku, Chiba 260-8670, Japan. E-mail: sima@med.m.chiba-u.ac.jp for AMI, we studied the ambulance records from Chiba City and Ichihara City, Japan. We perused the medical records of the admitting institutions for all patients arriving by ambulance with a diagnosis of AMI, reconfirmed the diagnoses, and ascertained the medical treatment given in the acute phase. We also determined the availability of equipment and personnel for cardiac care in the admitting institutions and the case-fatality rates. Based on this information, recommendations are made.

\section{Methods}

Study Population

From all 1992 ambulance records $(n=31,191)$ from the Fire Departments in Chiba City and Ichihara City, Chiba Prefecture, Japan, we determined that 401 patients were admitted to hospital for AMI. Thirteen patients were excluded because they were seen more than 2 weeks after the onset of symptoms. Of the remaining 388 patients admitted within 2 weeks after the onset of symptoms, we examined the medical records of the institutions to which the patients were finally admitted and treated, reconfirmed the diagnoses using MONICA criteria ${ }^{4}$ and determined what medical treatments were given. Briefly, the criteria for definite AMI were: (1) definite ECG changes; (2) probable ECG changes and abnormal enzymes; (3) typical symptoms and abnormal enzymes; or (4) fatal case with the appearance of fresh myocardial infarction and/or recent coronary occlusion found at necropsy. There were 171 patients who fulfillled the criteria, which included 168 patients admitted alive (Fig 1). Because observation periods were different among the institutions, we could evaluate outcome only by death occurring in the hospital. After hospital discharge, follow-up was impossible. As of 
Total Patients Transported by Ambulances of Fire

Departments of Chiba City and Ichihara City in 1992

$(\mathrm{n}=31,191)$
$\downarrow$
Noted by Doctors as AMI in Ambulance Records
$(\mathrm{n}=401)$

$\rightarrow$ Excluded: 13 Cases $>2$ weeks After Onset

Admitted $\leq 2$ Weeks After Onset

$(\mathrm{n}=388)$

$\leftarrow$ Investigation of Medical Records of Admitting Institutions (Met MONICA Criteria)

\begin{tabular}{|c|}
\hline $\begin{array}{l}\text { Definite AMI } \\
\qquad(\mathrm{n}=171)\end{array}$ \\
\hline
\end{tabular}

\begin{tabular}{c}
$\begin{array}{c}\text { Admitted Alive } \\
(\mathrm{n}=168)\end{array}$ \\
$\downarrow$ \\
\hline Age $<70$ y and Admitted $\leq 6 \mathrm{~h}$ \\
$(\mathrm{n}=77)$
\end{tabular}

Fig 1. Schematic representation of the selection process and sample attrition.

October 1992, Chiba City, the capital of Chiba Prefecture, had a population of 841,914 (7.4\% $\geq 65$ years of age) and an area of $272.4 \mathrm{~km}$. Ichihara City is located to the south of Chiba City, and had a population of $267,004(8.4 \% \geq 65$ years of age) and an area of $367.9 \mathrm{~km}^{2}$ Combined, these cities had a population of $1,108,918(7.6 \% \geq 65$ years of age) and an area of $640.3 \mathrm{~km}$ ?

\section{Classification of Admitting Institutions}

According to the availability of equipment and personnel for cardiac care, the admitting institutions were classified into 5 groups: Type A, PTCA or PTCR always available; Type B, PTCA or PTCR available only at certain times; Type $\mathrm{C}$, coronary angiography $(\mathrm{CAG})$ available but not PTCA or PTCR; Type D, CAG, PTCA or PTCR not available; and Type E, outpatient clinic only. In Chiba City there were 1 Type A, 5 Type B, 1 Type C, 38 Type D, and 471 Type $\mathrm{E}$ institutions, and in Ichihara City there were 0 Type A, 1 Type B, 1 Type C, 11 Type D, and 112 Type E institutions. In these 2 cities, only Type A institutions were equipped with a coronary care unit (CCU).

\section{Main Outcome Measure}

We examined the availability of recanalization treatment and various time periods; that is, the time from onset of symptoms to the call to the Fire Department (decision time), the time from the call to the Fire Department to the arrival of ambulance personnel at the patient's side, the time from the call to the Fire Department to arrival at the primary or admitting institution, and time from onset of symptoms to admission. In addition to age and sex, patient data such as infarct site, existence of hypotension, tachycardia on arrival, and previous myocardial infarction were used as measures of disease severity.

\section{Statistical Analyses}

The factors of sex, age, and hospital case-fatality rates were compared in relation to the type of treatment by Chisquare test. Comparisons between the discharged-alive group and the hospital-death group were also performed. The comparisons of age and the time periods between the discharged-alive group and the hospital-death group were done by Wilcoxon's test. Further, the factors associated with hospital death were evaluated by multiple logistic regression.

\section{Results}

Analysis of 388 Patients Admitted

Within 2 Weeks of Onset

The types of institutions and the final diagnoses of 388 patients admitted within 2 weeks after onset of symptoms of AMI are shown in Table 1. Of these, 262 patients were admitted to Type A, B or C institutions, with 144 patients being admitted to Type A institutions. Among 13 patients admitted to Type $\mathrm{E}$ institutions, there were 8 patients with no AMI, 4 patients with cardiopulmonary arrest, and 1 patient for whom there was no information. There were 171 patients who fulfillled the MONICA criteria, which included 4 patients with cardiopulmonary arrest upon arrival, 1 of whom survived. Possible AMI totalled 49 cases, with cardiopulmonary arrest in 39 of these. Among the 149 cases with the diagnosis of no AMI, there were 4 cases of cardiopulmonary arrest. Fatal cases with insufficient data numbered 11. Lack of information was present in 8 cases (lost medical records, permission for perusal was not obtained, etc). The time from onset of symptoms to admission for $47 \%$ of cases was within $2 \mathrm{~h}$, for $75 \%$ within $6 \mathrm{~h}$, and for $18 \%$ more than $12 \mathrm{~h}$. Finally, 67 patients $(40 \%$ of the patients with definite AMI admitted alive) were sent to institutions without CCU, and 21 patients (13\%) were sent to institutions not equipped to perform $\mathrm{CAG}$.

\section{Analysis of 168 Patients With Definite AMI Admitted Alive}

The characteristics of 168 patients with definite AMI admitted alive who received 4 types of treatment are shown in Table2. Fifty-two patients underwent emergency PTCA (including primary, rescue, and immediate PTCA), 6 patients had PTCR, 36 patients were given only intravenous thrombolysis and 74 patients were given conservative therapy. In the emergency PTCA and PTCR groups, the percentages of patients aged $<70$ years or who were male were higher than in the other groups. In the intravenous thrombolysis group, only $11.1 \%$ underwent emergency CAG.

\section{Comparison of the Discharged Alive} and the Hospital Mortality Groups

A comparison of data between patients who were discharged alive $(n=136)$ and those who died in the hospital $(n=32)$ is shown in Table 3 . The median age was lower and the percentage of males was higher in the discharged-alive group than in the hospital-death group. There were no significant differences in rates of anterior infarction, 
Table 1 Final Diagnosis of the 388 Patients $\leq 2$ Weeks After Onset of Acute Myocardial Infarction (AMI) and Type of Admitting Institution

\begin{tabular}{|c|c|c|c|c|c|c|}
\hline & \multicolumn{5}{|c|}{ Admitting institution } & \multirow{2}{*}{$\begin{array}{c}\text { Total } \\
(n=388)\end{array}$} \\
\hline & $\begin{array}{c}\text { Type A } \\
(n=144)\end{array}$ & $\begin{array}{l}\text { Type B } \\
(n=77)\end{array}$ & $\begin{array}{l}\text { Type } C \\
(n=41)\end{array}$ & $\begin{array}{c}\text { Type D } \\
(n=113)\end{array}$ & $\begin{array}{l}\text { Type E } \\
(n=13)\end{array}$ & \\
\hline Definite AMI & $103(2)$ & 27 & $19(1 *)$ & $22(1)$ & 0 & $171(4 *)$ \\
\hline Possible AMI & $7(6)$ & $11(10)$ & $4(2)$ & $25(19)$ & $2(2)$ & $49(39)$ \\
\hline No AMI or coronary death & $32(2)$ & 36 & 17 & $56(2)$ & 8 & $149(4)$ \\
\hline Fatal case with insufficient data & $1(1)$ & $1(1)$ & $1(1)$ & $6(6)$ & $2(2)$ & $11(11)$ \\
\hline Lack of information & 1 & 2 & 0 & 4 & 1 & 8 \\
\hline
\end{tabular}

Diagnosis of definite and possible AMI, no AMI or coronary death, and fatal cases with insufficient data were based on WHO MONICA criteria. Classification of admitting instiutions (Types A E) is described in Methods. No. patients with cardiopulmonary arrest on arrival is indicated in parenthesis. *One case survived.

Table 2 Characteristics of the 168 Patients With Definite AMI Admitted Alive Who Received 1 of 4 Types of Treatments

\begin{tabular}{|c|c|c|c|c|}
\hline & $\begin{array}{c}\text { Emergency } \\
\text { PTCA } \\
(n=52)\end{array}$ & $\begin{array}{c}\text { Emergency } \\
P T C R \\
(n=6)\end{array}$ & $\begin{array}{l}\text { Intravenous } \\
\text { thrombolysis } \\
\quad(n=36)\end{array}$ & $\begin{array}{c}\text { Conservative } \\
\text { therapy } \\
(n=74)\end{array}$ \\
\hline \multicolumn{5}{|l|}{ Demographics } \\
\hline Age $<70(\%)$ & 80.8 & 83.3 & 52.8 & 56.8 \\
\hline Male sex $(\%)$ & 90.4 & 83.3 & 66.7 & 66.2 \\
\hline \multicolumn{5}{|l|}{ Clinical findings } \\
\hline Onset of symptoms to admission $\geq 6 \mathrm{~h}(\%)$ & 15.4 & 0.0 & 11.1 & 40.5 \\
\hline Anterior infarction (\%) & 59.6 & 66.7 & 63.9 & 51.4 \\
\hline \multicolumn{5}{|l|}{ Hemodynamic findings on arrival } \\
\hline Systolic blood pressure $<100 \mathrm{mmHg}(\%)$ & 5.8 & 16.7 & 19.4 & 20.3 \\
\hline Pulse rate $\geq 100$ beats $/ \mathrm{min}(\%)$ & 15.4 & 33.3 & 16.7 & 27.0 \\
\hline \multicolumn{5}{|l|}{ Examination } \\
\hline Emergency CAG attempted (\%) & 100.0 & 100.0 & 11.1 & 2.7 \\
\hline Confirmation of recanalization by emergency $C A G(\%)$ & 90.4 & 83.3 & $75.0^{*}$ & $0.0 *$ \\
\hline Moderate or severe lung congestion (\%) & 5.8 & 0.0 & 22.2 & 27.0 \\
\hline Admitted to $C C U(\%)$ & 96.2 & 50.0 & 22.2 & 37.8 \\
\hline Hospital case fatality rates (\%) & 0.0 & 16.7 & 25.0 & 29.0 \\
\hline
\end{tabular}

*The ratio of confirmation of recanalization to emergency CAG attempted.

Table 3 Characteristics of the 168 Patients With Definite AMI Who Were Admitted Alive According to Outcome

\begin{tabular}{|c|c|c|c|}
\hline & $\begin{array}{l}\text { Discharged alive } \\
\text { group }(n=136)\end{array}$ & $\begin{array}{l}\text { Hospital death } \\
\text { group }(n=32)\end{array}$ & $p$ value \\
\hline \multicolumn{4}{|l|}{ Demographics } \\
\hline Age, median (range) & $61(35 \sim 88)$ & $73(53 \sim 92)$ & $<0.001$ \\
\hline Male sex (\%) & 81.6 & 40.6 & $<0.001$ \\
\hline Anterior infarcton (\%) & 54.4 & 71.9 & 0.094 \\
\hline \multicolumn{4}{|l|}{ Hemodynamic findings on arrival } \\
\hline Systolic blood pressure $<100 \mathrm{mmHg}(\%)$ & 9.6 & 40.6 & $<0.001$ \\
\hline Pulse rate $\geq 100$ beats $/ \mathrm{min}(\%)$ & 24.3 & 15.6 & 0.463 \\
\hline Previous myocardial infarction (\%) & 11.8 & 21.9 & 0.226 \\
\hline \multicolumn{4}{|l|}{ Institutions and examination } \\
\hline Admitted to institutions not equipped with $C A G(\%)$ & 7.4 & 37.5 & $<0.001$ \\
\hline Admitted to $C C U(\%)$ & 59.6 & 25.0 & $<0.001$ \\
\hline Emergency CAG attempted (\%) & 45.6 & 3.1 & $<0.001$ \\
\hline Confirmation of recanalization by emergency $C A G(\%)$ & 40.4 & 3.1 & $<0.001$ \\
\hline \multicolumn{4}{|l|}{ Time required for transfer, min median (range) } \\
\hline Onset of symptoms to call to Fire Department & $139(3 \sim 14,980)$ & $65(7 \sim 8,640)$ & 0.095 \\
\hline $\begin{array}{l}\text { Call to Fire Department to ambulance personnel's arrival } \\
\text { at patient's side }\end{array}$ & $4(1 \sim 12)$ & $4(2 \sim 10)$ & 0.175 \\
\hline Call to Fire Department to arrival at first institution & $22(8 \sim 101)$ & $21(8 \sim 40)$ & 0.511 \\
\hline Call to Fire Department to admission & $26.5(8 \sim 386)$ & $27(11 \sim 106)$ & 0.688 \\
\hline Onset of symptoms to admission & $190(20 \sim 15,000)$ & $112(21 \sim 8,640)$ & 0.033 \\
\hline
\end{tabular}

percentage of patients with a pulse rate $\geq 100$ beats/min on arrival, and previous myocardial infarction between the 2 groups. The percentages of patients with a systolic blood pressure less than $100 \mathrm{mmHg}$ on arrival and of those admitted to institutions not equipped to perform CAG (Type D) were significantly lower in the discharged-alive group than in the hospital-death group. The percentages of patients who were admitted to CCU, in whom emergency CAG was attempted, and in whom recanalization were confirmed were significantly higher in the discharged-alive group than 
Table 4 Odds Ratios and 95\% Confidence Intervals (95\% CI) for Hospital Deaths by Multiple Logistic Regression Analysis in Patients with Definite AMI Admitted Alive (n=168)

\begin{tabular}{|c|c|c|c|}
\hline & Odds ratio & $95 \% C I$ & $p$ value \\
\hline Age (10 year increments) & 1.48 & $0.89 \sim 2.47$ & 0.129 \\
\hline Male sex & 0.14 & $0.04 \sim 0.46$ & 0.002 \\
\hline Anterior infarction & 6.36 & $2.00 \sim 24.0$ & 0.003 \\
\hline Systolic blood pressure $<100 \mathrm{mmHg}$ on arrival & 13.80 & $3.84 \sim 59.8$ & 0.001 \\
\hline Pulse rate $\geq 100$ beats/min on arrival & 0.36 & $0.08 \sim 1.38$ & 0.157 \\
\hline Previous myocardial infarction & 2.19 & $0.47 \sim 9.83$ & 0.305 \\
\hline Time from onset of symptoms to call to the fire departments ( $1 \mathrm{~h}$ increments) & 0.98 & $0.97 \sim 1.01$ & 0.127 \\
\hline Time from call to Fire Department to admission (1 $\mathrm{h}$ increments) & 1.89 & $0.03 \sim 114$ & 0.760 \\
\hline \multicolumn{4}{|l|}{ Type of treatment } \\
\hline Conservative therapy & 1.00 & & \\
\hline Only intravenous thrombolysis & 0.55 & $0.15 \sim 1.85$ & 0.346 \\
\hline Emergency PTCA or PTCR & 0.07 & $0.003 \sim 0.56$ & 0.029 \\
\hline
\end{tabular}

in the hospital-death group.

The median time from onset of symptoms to admission was $190 \mathrm{~min}$ in the discharged-alive group and $112 \mathrm{~min}$ in the hospital-death group, with the difference being statistically significant. For other median time components, there were no significant differences between the 2 groups (Table 3).

\section{Multiple Logistic Regression Analysis for \\ Hospital Deaths of Definite AMI Patients}

The results of multiple logistic regression analysis of the factors that affected hospital deaths among the 168 patients with definite AMI admitted alive are shown in Table 4. As the age of patients increased in 10-year increments, the odds ratio for hospital death was 1.48 . The odds ratio of males versus females was 0.14 , which was significantly low. The odds ratios for deaths of patients with anterior infarction or systolic blood pressure less than $100 \mathrm{mmHg}$ on arrival were significantly high. Undergoing emergency PTCA or PTCR significantly decreased the hospital death rate compared with conservative therapy only (odds ratio $=0.07)$. Intravenous thrombolysis also decreased the rate (odds ratio $=0.55$ ), but its effect was not significant. There was no significant relationship between the incidence of hospital deaths and pulse rates on arrival, previous myocardial infarction, time from onset of symptoms to call to the Fire Department or interval from the call to the Fire Departments to admission.

If the type of treatment was not used for calculation, but rather admission to $\mathrm{CCU}$ or admission to institutions equipped with CAG, the odds ratio was 0.30 or 0.11 , respectively, values that were significantly low. Influences from other factors were almost the same as those from our previous results (data not shown).

\section{Discussion}

In order to decrease the mortality rates of AMI, the effects of improvement in supervision and treatment have been studied. Reports have described the shortening of decision time by means of early recognition of symptoms by education of patients, the 'chain of survival' concept advocated by the American Heart Association, thrombolytic therapy ${ }^{7-13}$ anticoagulant therapy, $7,8,14,15$ emergency PTCA, ${ }^{13,16-23}$ assisted circulation ${ }^{24,25}$ and a system to determine the effect of prehospital-initiated treatment of myocardial infarction? ${ }^{26,27}$

Many reports have shown that case-fatality rates of AMI patients arriving quickly at specialty institutions are decreased by recanalization therapy and assisted circulation in contrast to patients not so treated. However, even in a report of the Tokyo CCU network, considered as an ideal model of the Japanese AMI emergency medical system, only one quarter of AMI patients were admitted to a CCU? In order to improve survival rates in an entire area, it is necessary to increase the number of patients who can be accommodated by specialty institutions. To implement such reform, it is imperative in each particular area to fully understand the treatment situation of all patients who experience AMI. Previously, death certificates have often been examined to estimate the incidence of sudden cardiac death due to AMI, and to reevaluate all heart disease deaths $2^{29,30}$ In these studies, however, an evaluation of survivors was not conducted.

The present study is an analysis of all patients who used fire department ambulances in Chiba City and Ichihara City. It is acknowledged that there are patients who did not use these ambulances, patients whose cause of death was listed as cardiopulmonary arrest and 'acute heart failure', whose illnesses were not listed as AMI but later diagnosed as AMI, and whose AMI diagnosis occurred during admission. Therefore, this study may not have included all AMI patients, but AMI has a high degree of severity and the frequency that such patients request ambulances is high5, Also, there are few private ambulances in Japan. The incidence of definite AMI ( $\mathrm{n}=171$, male and female) that we found was 15 per 100,000 (total population, not age standardized) and that of AMI that included possible cases $(n=220)$ was 20 per 100,000 . This indicates that most AMI patients within these 2 cities may have been included in this investigation, as age standardized annual rates for men with AMI in the MONICA project in Japan were 25 per $100,000$ (population aged 25-75 years) $)^{31}$ We diagnosed AMI by means of not only progression of Minnesota codes on serial ECGs, cardiac enzyme levels twice the normal limit, and findings at necropsy according to MONICA diagnostic criteria, but also by results of echocardiograms and $\mathrm{CAG}$.

As an index of specialty institutions of cardiology, the medical treatment systems for recanalization therapy, the equipment for $\mathrm{CCU}$, and the existence of a full-time specialist of cardiology can be used. In the present study, the institutions were classified mainly by means of medical treatment systems for recanalization therapy. In both cities, there was only one with a CCU. We adopted type C institutions as a classification item in addition to the medical 
treatment system, with the rationale that the equipment for CAG probably means the existence of a full-time specialist. In the future, we will be able to use 'a fellow of Japanese Circulation Society' as an index.

The usefulness of emergency PTCA and PTCR has been shown in numerous studies! $17,32,33$ In the present study, the odds ratio of hospital death was significantly lower for the patients who underwent emergency PTCA or PTCR in comparison with the other groups, even though we considered age, sex and disease severity by multiple logistic regression. Also, among AMI patients who were considered eligible for recanalization therapy, the case-fatality rates of those who underwent emergency PTCA or PTCR were lower in comparison with those who underwent only intravenous thrombolysis or conservative therapy. As well, $89 \%$ of the patients with intravenous thrombolysis did not undergo emergency $\mathrm{CAG}$, and their infarcted arteries were not evaluated. Therefore, we distinguished intravenous thrombolysis only from emergency PTCA or PTCR. These findings from our retrospective study suggest the usefulness of emergency PTCA and PTCR, even though the advantages of a prospective randomized study are recognized. PTCA and PTCR as the primary treatment strategies are limited by the availability of institutions offering them and by the availability of personnel for cardiac catheterization and physicians qualified to perform angioplasty and recanalization. Because of this, intravenous thrombolysis has become established as the first line of therapy for AMI in suitable patients in the USA.

Chiba City and Ichihara City are neighboring towns of the Metropolis of Tokyo, and the population includes many office and factory workers, so we can consider them as typical Japanese cities. It was clear from a report of Keys et al that the incidence of coronary heart disease in Japan is low ${ }^{34}$ In the MONICA project, coronary rates for men in Germany, New Zealand, Australia, and Finland (1985-89) were $298-838$ per 100,000 , whereas the rates in Japan were 25 per 100,00035 From a report of the National Heart, Lung and Blood Institute of the National Institutes of Health in the US, mortality from coronary heart disease in Japan is the lowest in the world 36 Japan is small and there are many institutions equipped with $\mathrm{CAG}$, and because all citizens have health insurance, physicians can easily provide emergency PTCA or PTCR. Results from a questionnaire in 1994 from 170 institutions from all over Japan showed that over $50 \%$ of patients received primary PTCA 37 However, these were mostly patients admitted to specialty institutions of cardiology. In a report from the US in 1990, of an estimated 675,000 patients admitted to hospitals with a diagnosis of AMI, less than $20 \%$ received fibrinolytic therapy, and $15 \%$ did not receive fibrinolytic therapy even though they were ideally suitable for thrombolysis 38 This suggests that worldwide, in spite of the eligibility for recanalization therapy, there must be many who do not receive emergency PTCA, PTCR, or thrombolytic therapy because they were admitted to institutions without the personnel or equipment for their administration.

In the present study, 101 patients $(61 \%)$ with definite AMI who were admitted alive were finally conveyed to a Type A institution. Unless there were contraindications, emergency PTCA or PTCR were done on the eligible patients irrespective of the time of onset, and there were no hospital deaths among the patients who underwent these procedures. The patients who were admitted to a CCU and those who were admitted to institutions equipped with
CAG had a significantly low risk of hospital death. From these findings, we conclude that it is important for AMI patients to be admitted to a CCU and undergo medical treatment by cardiovascular specialists in institutions with the capability to perform CAG, even though there may not be provision for recanalization therapy. Thus, this study showed the importance of the selection of institutions for AMI patients. In total, $40 \%$ of the patients with definite AMI admitted alive were sent to institutions without CCU. Enough CCU and the proper transfer of AMI patients to CCU are necessary in an emergency system. In particular, from a realistic point of view including costs and time periods, we should first improve the transfer system from primary institutions to appropriate specialty institutions of cardiology.

As only one Type A institution considered primary PTCA as the first treatment for AMI, the numbers of PTCR and intravenous thrombolysis-only therapies were smaller than that of emergency PTCA. Therefore, there may be a bias among the results of this study. Because many patients are transferred to this Type A institution from Type D and E institutions, an improvement in the accuracy of diagnosis in primary institutions is desirable in order to make the best use of the Type A institution. The rates of definite AMI in hospital discharge statistics were reported to be $58-64 \%$ in trials in which symptoms of suspected AMI were considered as diagnostic 39,40 and $94 \%$ in a trial in which chest pain accompanied by ST segment elevation or depression of the ECG was considered as diagnostic.1

In the European Myocardial Infarction Project (EMIP), the benefits and risks of prehospital thrombolytic therapy were evaluated, and the accuracy of the prehospital diagnosis was high (88\%). ${ }^{27}$ Compared with the findings in the present study whereby AMI was diagnosed or suspected in the admitting institutions in the acute phase, the rate of definite AMI was $44.1 \%$ (56.7\% if we include possible AMI) and, even if we restrict figures to those patients who were admitted alive, it was $50.8 \%(53.8 \%$ if we include possible AMI). With this relatively low rate of accuracy, it might be difficult to make good use of Type A institutions. We think that a program of consultations with specialists, including transmission of ECG data, is necessary to improve the diagnostic accuracy in primary institutions for patients in the acute phase of AMI.

Among 168 patients with definite AMI who were admitted alive, the time from onset of symptoms to admission was significantly longer in the discharged-alive group than in the hospital-death group. There is the possibility that the more severe the patient's condition (eg, shock), the sooner the Fire Department was called and the patient conveyed to the institutions. ${ }^{42}$ With multiple logistic regression of disease severity, there was no significance between the time of onset of symptoms to time of call to the Fire Department, time from the call to the Fire Department to admission and hospital death.

\section{Conclusions}

The hospital case-fatality rates of AMI patients who underwent emergency PTCA or PTCR were lower than those receiving other therapies. The admission to a $\mathrm{CCU}$ or institutions equipped with $\mathrm{CAG}$ also decreased the hospital case-fatality rate. Because $40 \%$ of the patients with definite AMI admitted alive were sent to institutions without CCU, it is essential that enough CCU are available through an 
improvement in the cooperation between various types of institutions in order to raise the precision of the diagnosis in the acute phase, and to correctly transfer AMI patients to a CCU.

\section{Acknowledgments}

The authors appreciate the cooperation of the fire departments and medical institutions of Chiba City and Ichihara City and thank them for their assistance in this study.

\section{References}

1. The GUSTO Angiographic Investigators: The effects of tissue plasminogen activator, streptokinase, or both on coronary-artery patency, ventricular function, and survival after acute myocardial infarction. N Engl J Med 1993; 329: 1615-1622

2. Tunstall-Pedoe H, Kuulasmaa K, Amouyel P, Arveiler D, Rajakangas AM, Pajak A: Myocardial infarction and coronary deaths in the World Health Organization MONICA Project: registration procedures, event rates, and case-fatality rates in 38 populations from 21 countries in four continents. Circulation 1994; 90: 583-612

3. Ellerbeck EF, Jencks SF, Radford MJ, Kresowik TF, Craig AS, Gold JA, et al: Quality of care for medicare patients with acute myocardial infarction: A four-state pilot study from the cooperative cardiovascular project. JAMA 1995; 273: 1509-1514

4. Tuomilehto J, Kuulasmaa K: WHO MONICA Project: assessing CHD mortality and morbidity. Int J Epidemiol 1989; 18: S38-S45

5. O'Doherty M, Tayler DI, Quinn E, Vincent R, Chamberlain DA: Five hundred patients with myocardial infarction monitored within one hour of symptoms. BMJ 1983; 286: $1405-1408$

6. Cummins RO, Ornato JP, Thies WH, Pepe PE: Improving survival from sudden cardiac arrest: the 'chain of survival' concept (A statement for health professionals from the advanced cardiac life support subcommittee and the emergency cardiac care committee, American Heart Association). Circulation 1991; 83: 1832-1847

7. The International Study Group: In-hospital mortality and clinical course of 20891 patients with suspected acute myocardial infarction randomized between alteplase and streptokinase with or without heparin. Lancet 1990; 336: 71-75

8. ISIS-3 (Third International Study of Infarct Survival) Collaborative Group: ISIS-3: a randomized comparison of streptokinase versus tissue plasminogen activator versus anistreplase and of aspirin plus heparin versus aspirin alone among 41,299 cases of suspected acute myocardial infarction. Lancet 1992; 339: 753-770

9. The GUSTO investigators: An international randomized trial comparing four thrombolytic strategies for acute myocardial infarction. N Engl J Med 1993; 932: 673-682

10. Chesebo JH, Knatterud G, Roberts R, Borer J, Cohen LS, Dalen J, et al: Thrombolysis in Myocardial Infarction (TIMI) trial, phase I: a comparison between intravenous tissue plasminogen activator and intravenous streptokinase: Clinical findings through hospital discharge. Circulation 1987; 76: $142-154$

11. Nagao K, Kanmatsuse K, Kajiwara N: Thrombolytic therapy for acute myocardial infarction-effects, problems and strategies. Jpn Circ J 1994; 58: 885-893

12. Kanemoto N, Goto Y, Hirosawa K, Kawai C, Kimata S, Yui Y, et al: Intravenous recombinant tissue-type plasminogen activator in patients with acute myocardial infarction: A report from multicenter thrombolysis trial. Jpn Circ J 1990; 54: 71-81

13. Iwasaki K, Kusachi S, Kita T, Taniguchi G, Tsuji T: Effects of reperfusion on left ventricular ejection fraction and volume after acute myocardial infarction. Jpn Circ J 1992; 56: 783-792

14. Chalmers TC, Matta RJ, Smith JH, Kunzler AM: Evidence favoring the use of anticoagulants in the hospital phase of acute myocardial infarction. N Engl J Med 1977; 297: 1091-1096

15. Moriyama Y, Ogawa H, Oshima S, Takazoe K, Honda Y, Hirashima $\mathrm{O}$, et al: Captoril reduced plasminogen activator inhibitor activity in patients with acute myocardial infarction. Jpn Circ J 1997; 61: $308-314$

16. Grines CL, Browne KF, Marco J, Rothbaum D, Stone GW, O'Keefe J, et al: A comparison of immediate angioplasty with thrombolytic therapy for acute myocardial infarction. N Engl J Med 1993; 328: 673-679

17. Ellis SG, Van de Werf F, Ribeiro-dasilva E, Topol EJ: Present status of rescue coronary angioplasty: current polarization of opinion and randomized trials. J Am Coll Cardiol 1992; 19: 681-686

18. Topol EJ, Califf RM, George BS, Kereiakes DJ, Abbottsmith CW,
Candela RJ, et al: A randomized trial of immediate versus delayed elective angioplasty after intravenous tissue plasminogen activator in acute myocardial infarction. $N$ Engl J Med 1987; 317: 581-588

19. The TIMI Research Group: Immediate versus delayed catheterization and angioplasty following thrombolytic therapy for acute myocardial infarction TIMI II A results. JAMA 1988; 260: $2849-2858$

20. Simoons ML, Arnold AER, Betriu A, de Bono DP, Col J, Dougherty FC, et al: Thrombolysis with tissue plasminogen activator in acute myocardial infarction: no additional benefit from immediate percutaneous coronary angioplasty. Lancet 1988; 1: 197-202

21. The TIMI Study Group: Comparison of invasive and conservative strategies after treatment with intravenous tissue plasminogen activator in acute myocardial infarction: Results of the thrombolysis in myocardial infarction (TIMI) phase II trial. $N$ Engl J Med 1989; 320: $618-627$

22. Iwasaki K, Kusachi S, Hina K, Nishiyama O, Kondo J, Kita T, et al: Acute left main coronary artery obstruction with myocardial infarction: Reperfusion strategies, and the clinical and angiographic outcome. Jpn Circ J 1993; 57: 891-897

23. Sumii K, Hayashi Y, Oka Y, Taniguchi C, Maeda Y, Watanabe M, et al: The short- and long-term prognosis for acute myocardial infarction after emergency coronary angioplasty. Jpn Circ J 1993; 57: 1137-1149

24. Ohman EM, George BS, White CJ, Kern MJ, Gurbel PA, Freedman RJ, et al: Use of aortic counterpulsation to improve sustained coronary artery patency during acute myocardial infarction: Result of a randomized trial. Circulation 1994; 90: $792-799$

25. Mori Y, Ueno K, Hattori A, Kim T, Aoyama T, Segawa T, et al: Emergency cardiopulmonary bypass support in patients with cardiac arrest caused by myocardial infarction. Artif Organs 1994; 18: 698-701

26. Weaver WD, Cerqueira M, Hallstrom AP, Litwin PE, Martin JS, Kudenchuk PJ, et al: Prehopital-initiated versus hospital-initiated thrombolytic therapy: The Myocardial Infarction Triage and Intervention Trial. JAMA 1993; 270: 1211-1216

27. The European Myocardial Infarction Project Group: Prehospital thrombolytic therapy in patients with suspected acute myocardial infarction. N Engl J Med 1993; 329: 383-389

28. Aoki H, Takano T, Haze K, Arima S, Tateda K, Hayasaki K, et al: Prehospital care of acute myocardial infarction in Japan: problems in 6 representative areas. J Jpn Soc Intensive Care Med 1994; 1: 85-93 (in Japanese)

29. Hayashi S, Toyoshima H, Tanabe N, Miyanishi K: Daily peaks in the incidence of sudden cardiac death and fatal stroke in Niigata Prefecture. Jpn Circ J 1996; 60: 193-200

30. Yamashita T, Ozawa H, Aono H, Hosokawa H, Saito I, Ikebe T: Heart disease deaths on death certificates re-evaluated by clinical records in a Japanese city. Jpn Circ J 1997; 61: 331-338

31. Inagaki Y: Heart disease in Japan. In: Japan Heart Foundation, editor. Strategically heart disease protection to the 21 st Century: proposal to heart disease protection bringing under control. Tokyo, Japan: Daiichi-Houki Publishing, 1991: 13-26 (in Japanese)

32. Stone GW, Grines CL, Rothbaum D, Browne KF, O'Keefe J, Overlie PA, et al: Analysis of the relative costs and effectiveness of primary angioplasty versus tissue-type plasminogen activator: the primary angioplasty in myocardial infarction (PAMI) trial. J Am Coll Cardiol 1997; 29: $901-907$

33. Rentrop KP, Blanke H, Karsch KR, Kreuzer H: Initial experience with transluminal recanalization of the recently occluded infarctrelated coronary artery in acute myocardial infarction: comparison with conventionally treated patients. Clin Cardiol 1979; 2: 92-105

34. Kimura N, Keys A: Coronary heart disease in seven countries. X Rural southern Japan. Circulation 1970; 41(4 Suppl): I-101-I-112

35. Lowel H, Dobson A, Keil U, Herman B, Hobbs MST, Stewart A, et al: Coronary heart disease case fatality in four countries: a community study. Circulation 1993; 88: 2524-2531

36. National Heart, Lung, and Blood Institute: Annual report fiscal year 1995: Report on international activities, October 1, 1994. NHLBI, September 30, 1995

37. Motomiya T, Kanmatsuse K, Shiroya M: Discussion considered differences with Europe and USA: Future direction and task in Japan. In: Yazaki Y, Yamaguchi T, Shimada K, editors. A worldwide forum for comments and opinions on heart disease, Vol. 3 . Tokyo, Japan: Life Science Publishing, 1995: 26-28 (in Japanese)

38. Muller DWM, Topol EJ: Selection of patients with acute myocardial infarction for thrombolytic therapy. Ann Intern Med 1990; 113: 949-960

39. ISIS-2 (Second International Study of Infarct Survival) Collaborative Group: Randomized trial of intravenous streptokinase, oral aspirin, 
both, or neither among 17,187 cases of suspected acute myocardial infarction: ISIS-2. Lancet 1988; 2: 349-360

40. Wilcox RG, Von der Lippe G, Olsson CG, Jensen G, Skene AM, Hampton JR: Trial of tissue plasminogen activator for mortality reduction in acute myocardial infarction: Anglo-Scandinavian Study of Early Thrombolysis (ASSET). Lancet 1988; 2: 525-530

41. Gruppo Italiano per lo Studio della Streptochinasi nell'Infarto
Miocardico (GISSI): Effectiveness of intravenous thrombolytic treatment in acute myocardial infarction. Lancet 1986; 1: 397-402

42. Takano T, Tanaka K, Katoh T, Kojima H, Takada K, Honda T, et al: Current situation of acute myocardial infarction at Tokyo: summation result of CCU network. J Jpn Med Assoc 1986; 96: 2103-2109 (in Japanese) 